\title{
Use of mobile phones and risk of brain tumours: update of Danish cohort study
}

\author{
(๑) (1) OPEN ACCESS
}

\author{
Patrizia Frei postdoctoral research fellow ${ }^{1}$, Aslak H Poulsen doctoral student ${ }^{1}$, Christoffer Johansen \\ professor ${ }^{1}$, Jørgen H Olsen director ${ }^{1}$, Marianne Steding-Jessen statistician ${ }^{1}$, Joachim Schüz head \\ of section ${ }^{2}$
}

${ }^{1}$ Institute of Cancer Epidemiology, Danish Cancer Society, Strandboulevarden 49, 2100 Copenhagen, Denmark; ${ }^{2}$ International Agency for Research on Cancer (IARC), Section of Environment and Radiation, 150 Cours Albert Thomas, 69372 Lyon CEDEX 08, France

\author{
Abstract \\ Objective To investigate the risk of tumours in the central nervous \\ system among Danish mobile phone subscribers. \\ Design Nationwide cohort study. \\ Setting Denmark.
}

Participants All Danes aged $\geq 30$ and born in Denmark after 1925, subdivided into subscribers and non-subscribers of mobile phones before 1995.

Main outcome measures Risk of tumours of the central nervous system, identified from the complete Danish Cancer Register. Sex specific incidence rate ratios estimated with log linear Poisson regression models adjusted for age, calendar period, education, and disposable income.

Results 358403 subscription holders accrued 3.8 million person years. In the follow-up period 1990-2007, there were 10729 cases of tumours of the central nervous system. The risk of such tumours was close to unity for both men and women. When restricted to individuals with the longest mobile phone use-that is, $\geq 13$ years of subscription-the incidence rate ratio was 1.03 (95\% confidence interval 0.83 to 1.27$)$ in men and 0.91 ( 0.41 to 2.04 ) in women. Among those with subscriptions of $\geq 10$ years, ratios were 1.04 (0.85 to 1.26$)$ in men and 1.04 (0.56 to $1.95)$ in women for glioma and 0.90 (0.57 to 1.42) in men and $0.93(0.46$ to 1.87 ) in women for meningioma. There was no indication of dose-response relation either by years since first subscription for a mobile phone or by anatomical location of the tumour - that is, in regions of the brain closest to where the handset is usually held to the head.

Conclusions In this update of a large nationwide cohort study of mobile phone use, there were no increased risks of tumours of the central nervous system, providing little evidence for a causal association.

\section{Introduction}

The number of mobile phone users is constantly increasing with more than five billion subscriptions worldwide in 2010. ${ }^{1}$ The widespread use of mobile phones has led to concerns regarding potential adverse health effects, particularly tumours of the central nervous system, of which the brain is the part most exposed to the radio frequency electromagnetic fields emitted by an operating mobile phone held to the ear. So far, the mechanism of potential non-thermal interaction between radio frequency electromagnetic fields and living systems is unknown. ${ }^{2}$ The results of the Interphone study, the largest international case-control study on this topic, generally suggest no increased risk of glioma or meningioma. ${ }^{3}$ For glioma, however, an increased risk (odds ratio $1.40,95 \%$ confidence interval 1.03 to 1.89 ) was observed in 364 people with more than 1640 hours of cumulative use. Results for long term mobile phone users ( $\geq 10$ years) remain scarce, and all epidemiological studies are based on few cases. ${ }^{4}$ In addition, most studies have been retrospective case-control studies with self reported data on mobile phone use, which are prone to bias, particularly random reporting bias and differential recall bias for cases and controls, which hampers the risk estimation and precludes firm conclusions. ${ }^{56}$

The only cohort study investigating mobile phone use and cancer to date is a Danish nationwide study comparing cancer risk of all 420095 people who had signed a mobile phone contract with a phone company (subscribers) from 1982 (the year such phones were introduced in Denmark) until 1995, with the corresponding risk in the rest of the adult population with follow-up to $1996^{7}$ and then $2002{ }^{8}$ The study found no evidence of any increased risk of brain or nervous system tumours or any cancer among mobile phone subscribers. There was, however, a decreased risk (standardised incidence ratio $0.66,0.44$ to 0.95 ) of developing a tumour of the brain or nervous system in people who had had a subscription for more than 10 years, but this result was based on only 28 cases. ${ }^{8}$ In addition, it was observed that male mobile phone subscribers were at a lower risk (standardised incidence ratio $0.88,0.86$ to 0.91 ) of developing 
tobacco related cancers. Additional investigations showed that early male subscribers probably constituted a unique subgroup of people with a higher income and therefore a potentially distinct risk profile, particularly lower tobacco consumption. ${ }^{8}$ We followed up the mobile phone subscriber study to 2007 , with a focus on tumours of the central nervous system. Longer follow-up increased the numbers of person years for subscribers, particularly in long term subscribers ( $\geq 10$ years), in whom the total of person years under risk increased from 170000 to 1.2 million. This allowed more detailed analysis of long term subscribers and topographical and morphological subtypes of intracranial central nervous system tumours. In addition, we were able to obtain information on socioeconomic status on an individual level, allowing adjustment for education and income when estimating risks related to mobile phone use.

\section{Methods}

Since 1 April 1968, all Danish residents have been registered in the central population register. At birth they are assigned a unique personal identification number that is used in all national registers, ensuring accurate linkage of information among these registers. ${ }^{9}$ This system enables researchers to conduct purely register based cohort studies for exposure data available from respective registries, as the follow-up of vital status, migration, and many health outcomes, in particular cancer, can be done by computerised linkage on an individual level with an exact calculation of person years at risk. Such a design has been used to follow adult people with a mobile phone contract (subscribers) for risk of disease compared with the rest of the Danish adult population; in other words, the whole Danish adult population was subdivided into subscribers and non-subscribers of mobile phones and followed up for incidence of cancer and other diseases. $^{781011}$

\section{Identification of mobile phone subscribers}

The collection of mobile phone subscription records has been described in detail previously. ${ }^{7}$ In brief, 723421 records for 1982-95 were obtained from the Danish network operators. Exclusion criteria included corporate subscriptions ( $n=200507)$ and others, as shown in figure $1 \Downarrow$. In the present analysis focusing on central nervous system tumours, we left censored the subscription date of individuals with a subscription before 1987 (1.8\% of all subscribers) to 1 January 1987 because handheld handsets were introduced in Denmark only in 1987 and cranial exposure from car phones (available from 1982) is much lower than exposure from mobile phones held to the head.

\section{Cohort definition}

In the previous follow-ups of the subscriber study information on socioeconomic factors was not available on an individual level, and the comparison of the average income of subscribers and non-subscribers showed higher average income in the subscriber group, thereby suggesting potential confounding. ${ }^{8}$ To overcome this limitation by obtaining access to individual data on socioeconomic factors, we conducted our study in the CANULI ("cancer og social ulighed") cohort, a register based Danish cohort study conducted at the Institute of Cancer Epidemiology on social inequality and cancer. ${ }^{9}$ This approach of restricting the mobile phone study to the CANULI cohort has been applied previously. ${ }^{12}$ The CANULI study included all Danes born in Denmark in 1925 or later and alive in 1990 who did not emigrate from the country before 1 January 1990. Entry into the CANULI cohort was at age 30 because younger people might have still been in the educational system. Descendants of immigrants were not included, as they comprised a small and heterogeneous group, and information on their education, if acquired abroad, was not systematically recorded in the register. The CANULI cohort is therefore a nationwide cohort of all Danes aged 30 or older and born after 1925 in Denmark. Because of the eligibility criteria of CANULI, not all original members of the mobile phone study were part of CANULI and therefore the original sample size became somewhat smaller. We had 3.21 million Danes for follow-up and the number of the mobile phone subscribers was reduced by 54350 individuals compared with the previous design. We decided that the advantage of obtaining individual level socioeconomic data and keeping a national representative cohort study clearly outweighed the seeming disadvantage of a reduction of the still large sample size.

From the CANULI study we obtained information on highest attained education and disposable income from the population based Integrated Database for Labour Market Research from 1990 onwards. Disposable income was calculated from household income after taxation and the number of people in the household, deflated according to the 2000 value of the Danish Crown. Information on cancer diagnosis was available from the Danish Cancer Register, which provides accurate and virtually complete nationwide ascertainment of cancers since 1943 , including benign tumours of the central nervous system. ${ }^{13}$ Cancers were classified according to a modified Danish version of ICD-10 (the international classification of diseases, 10th revision). ${ }^{14}$ Topography and morphology were categorised according to the first revision (ICD-O1) (until 2003) and third revision (ICD-O3) (2004-2007) of the international classification of diseases for oncology. ${ }^{15}$ Date of birth, sex, date of emigration, or date of death were available for each cohort member from the Danish central population register.

For the present analysis, follow-up for the occurrence of cancer started at age 30 or 1 January 1990, whichever occurred later, and ended on the date of first diagnosis of cancer (except for non-melanoma skin cancer), date of death, date of emigration, or 31 December 2007, whichever came first. Figure 2 shows the definition of the observation periods of collection of exposure data and follow-up for cancer outcome by age and calendar time in the study cohort $\downarrow$. We excluded from analyses any people with a history of cancer before entry into the study (except for non-melanoma skin cancer); this led to the exclusion of 3117 subscribers from analyses (370 of whom had cancer after their first subscription). To reduce the potential for reverse causation bias - that is, people purchasing a mobile phone because of early symptoms of their disease-we defined the person time within the first year of subscription as unexposed in the analyses. Some 4216 mobile phone subscribers who met the CANULI eligibility criteria were censored either before their first subscription (2660 subscribers) or within the first year of subscription (1556 subscribers); they therefore did not contribute any exposed person time to the study. In the present analyses, 358403 people therefore contributed to exposed person time at risk.

\section{Statistical analysis}

We used log linear Poisson regression models to estimate incidence rate ratios for cancer diagnoses for exposed person time (in people who had had mobile phone subscriptions for at least a year) compared with unexposed person time (non-subscribers or subscribers of less than a year). To investigate a potential dose-response relation between exposure and outcome, we further categorised the exposed person time according to years since first subscription, as in our previous 
analyses and most of the case-control studies (1-4, 5-9, $\geq 10$ years of subscription). ${ }^{378}$ When the number of cases allowed it, we subdivided the $\geq 10$ years category into $10-12$ years and $\geq 13$ years to allow a separate investigation of an even longer period.

All analyses were stratified by sex and adjusted for age in five year age groups $(30-34,35-40$, etc, to $\geq 75)$ and by calendar period (1990-5, 1996-2002, 2003-7) (basic model). Additionally, we adjusted analyses for highest attained education (basic school/high school, vocational training, higher education, unknown (3.7\%)) and disposable income (lowest (1st quarter), middle (2nd-3rd quarter), highest (4th quarter), and unknown $(4.1 \%)$ ) (fully adjusted model). In the results, we have shown only the fully adjusted models, unless the results for basic and fully adjusted models differed substantially. All covariates and exposure variables were included categorically, and people were allowed to change between category levels over time.

We looked at all cancers combined (ICD-10 C00-D48), cancers related to smoking (as this group has shown a reduced risk in previous follow-ups; ICD-10 C09-16, C22, C25, C32-34, C39, C53, C64, C67, D09.0, D30.3, D41.4), ${ }^{78}$ and, most importantly, the group of tumours of the central nervous system (including benign tumours) because of exposure of the brain when the phone is held to the head (ICD-10 C70-72, C75, D32-33, D35, D42, D44). We separately investigated intracranial tumours categorised according to ICD-O morphology and topography codes (glioma, meningioma, and others/unspecified). Among gliomas, we separately examined the different anatomical sites to investigate whether the risk is highest for the temporal lobe with highest absorption of energy emitted from a mobile phone held to the ear. ${ }^{16}$ All anatomical sites with less than 10 exposed cases and the groups without specification of the topography (C71.8 (overlapping lesion of brain) and C71.9 (brain, unspecified)) were classified into the group "other and unspecified." Smoking related cancers were classified according to the system of Olsen et al, ${ }^{17}$ covering cancers of the buccal cavity and pharynx, digestive organs, respiratory system, urinary tract, and cervix.

The study was entirely based on record linkage, and therefore required no personal contact with participants. All statistical analyses were performed in SAS 9.1.

\section{Results}

From 1990 to 2007, 358403 subscription holders beyond the first year of subscription accrued 3.8 million person years, with male subscribers providing nearly all person years (3.2 million). During follow-up, 122302 cases of cancer occurred in men and 133713 in women (table $1 \Downarrow$ ); in 5111 men and 5618 women these were tumours of the central nervous system.

The incidence rate ratio for all cancers was slightly decreased in men (incidence rate ratio $0.96,95 \%$ confidence interval 0.95 to 0.98 ) but not in women $(1.02,0.98$ to 1.06$)$. When we restricted the outcome to smoking related cancers, the estimate in men was decreased $(0.93,0.90$ to 0.96$)$, decreasing to 0.87 ( 0.81 to 0.93 ) in people with 13 or more years of subscription. Further analyses showed that the decreased incidence rate ratio for smoking related cancers was restricted to men with basic or vocational training $(0.91,0.89$ to 0.94$)$. In the higher education group (men with $>12$ years of education), the association between mobile phone use and smoking related cancers was close to unity (1.01, 0.93 to 1.09 ), strongly suggesting a lack of confounding by smoking in this subgroup. For tumours of the central nervous system, the incidence rate ratio was consistently close to 1 in women and men, both overall and when stratified by years since first subscription, and also when restricted to men in the highest education group (table 1).

Analyses by morphological subtype of intracranial central nervous system tumours found a slightly but non-significantly increased incidence rate ratio for glioma in men $(1.08,0.96$ to 1.22). The incidence rate ratio was highest in the shortest term users (1-4 years: 1.20, 0.96 to 1.22), and beyond five years of use numbers were only slightly raised, and there was no dose-response effect with increasing years of subscription (table $2 \Downarrow)$. In women, there was no association between mobile phone subscription and glioma regardless of duration (table 2). For meningioma, there was a reduction in risk of $22 \%$ for male subscribers, with some variations by years of follow-up but again no indication of dose-response relation. In women, numbers were small, but there was no sign of increased incidence rate ratios for meningioma (1.02, 0.71 to 1.47$)$. With regard to other and unspecified intracranial tumours of the central nervous system, estimates were non-significantly increased in men (incidence rate ratio $1.12,0.95$ to 1.33 ) and women $(1.19,0.85$ to 1.67$)$, but with no clear indication of a dose-response effect (table 2).

Further subdivision of gliomas in men by site (table $3 \Downarrow$ ) showed a marginally increased incidence rate ratio for the temporal lobe $(1.13,0.86$ to $1.48 ; n=65)$. When we stratified data by duration of follow-up, the highest estimates were seen in the periods 1-4 and 5-9 years of follow-up (incidence rate ratio 1.35, 0.83 to $2.20, \mathrm{n}=18$; and $1.31,0.89$ to $1.92, \mathrm{n}=29$, respectively), but decreased for subscribers of 10 or more years $(0.81,0.50$ to $1.32, \mathrm{n}=18)$. For other sites, the highest incidence rate ratio was found for the occipital lobe $(1.47,0.87$ to $2.48, \mathrm{n}=18)$, with the highest estimate for the shortest time users (1-4 years) (2.50, 1.18 to $5.31, \mathrm{n}=8$ ), and a non-significantly increased incidence rate ratio of $1.36(0.57$ to $3.23, n=6)$ for subscribers of 10 or more years. The incidence rate ratio for parietal lobe tumours was non-significantly decreased $(0.73,0.50$ to $1.05, \mathrm{n}=33)$. A significantly increased estimate was seen for "other and unspecified" sites $(1.35,1.05$ to $1.75, \mathrm{n}=77)$, which persisted when restricted to $\geq 10$ years of exposure $(1.44,1.00$ to 2.06 , $\mathrm{n}=35$ ). To further investigate this finding, we estimated the incidence rate ratios for each subgroup separately. The highest estimate was found for the cerebral ventricle $(2.58,1.08$ to 6.15$)$ but was based on only eight cases. Non-significantly increased incidence rate ratios were found for the unspecific groups "overlapping lesion of brain" $(1.34,0.92$ to $1.95, n=35)$ and "brain, unspecified" ( $1.31,0.86$ to $1.99, \mathrm{n}=29)$ respectively. In long term subscribers ( $\geq 10$ years), incidence rate ratios for these groups were 1.48 (0.92 to $2.67, \mathrm{n}=13$ ) and 1.62 (1.00 to 2.60, $\mathrm{n}=21$ ), respectively.

\section{Discussion}

In this second update of a large nationwide cohort of 358403 mobile phone subscribers in Denmark, we observed no overall increased risk of tumours of the central nervous system or for all cancers combined associated with use of mobile phones. With regard to the major histological subtypes of intracranial tumours of the central nervous system, there were decreased risk estimates for meningioma and non-significantly increased risks for glioma in men only, but there was no increase in risk estimates with increasing time since first subscription.

Importantly, there was no increase of glioma in the temporal lobes in long term subscribers, as the temporal lobe has been described as the region of the brain with highest absorption of energy emitted from mobile phones. ${ }^{16}$ 


\section{Comparison with previous follow-ups and other studies}

Most results of the present study are comparable with the results of the previous follow-up of mobile phone subscribers up to $2002 .^{8}$ That study, however, found a significant reduction in risk of tumours of the brain and nervous system in long term subscribers (standardised incidence ratio $0.66,95 \%$ confidence interval 0.44 to 0.95 ), based on 28 cases, which was suggested to be a result of chance. Our present study supports this interpretation as we also found an incidence rate ratio close to unity based on 316 cases when we investigated $\geq 10$ years of exposure. We had sufficiently large numbers to simultaneously investigate risk by tumour type (especially glioma), duration of follow-up, and sex. We found no dose-response relation with regard to years of subscription or to the anatomical site of the glioma (temporal lobe). With regard to other epidemiological studies, in 2010 Hardell et al found increased risks for glioma for both short and long term users. ${ }^{18}$ For those who had died, data on exposure were collected from relatives up to 11 years after death. No validation of this approach was conducted, making it impossible to assess the impact of the likely and potentially large recall bias. Most other studies to date have found no evidence for an increased risk of glioma in short term users ( $\leq 10$ years), and for longer latencies results were limited by small numbers. ${ }^{34}$ The largest case-control study to date (Interphone, including 13 countries) found a significantly increased risk of glioma for the highest tenth of cumulative time that mobile phones were used (call time), but bias and error prevented a causal interpretation. ${ }^{3}$ Regarding meningioma, our results are consistent with most studies in finding no increased risk. ${ }^{4}$ The risk estimate was even slightly decreased in men, which was also observed in some other studies. ${ }^{3}{ }^{19}$ The risk in women was close to unity. Also, population level ecological studies of central nervous system tumours and incidence rates for glioma after the introduction of mobile phones rule out mobile phones as a strong independent risk factor. ${ }^{20-23}$ Moreover, results from in vivo and in vitro studies do not provide convincing evidence for an effect of exposure to radio frequency electromagnetic fields at non-thermal intensity levels on carcinogenicity or genotoxicity, and a potential biological mechanism has not yet been identified. ${ }^{2}$

\section{Strengths and limitations of the study}

Our nationwide cohort study with objective register based data on both exposure and cancer outcome practically eliminates loss to follow-up, which was only $2.2 \%$, and provides accurate and virtually complete nationwide ascertainment of cancers. Compared with the follow-up to $2002,{ }^{8}$ the additional five years of follow-up increased the number of person years in people with a mobile phone subscription for at least 10 years by a factor of seven (1.2 million versus 170000 person years). Also, the number of cases of tumours of the central nervous system in long term subscribers increased from 28 to 316 - that is, by a factor greater than 10 . These marked increases allowed calculation of more robust estimates and allowed both analyses of subtypes of intracranial tumours of the central nervous system and separate investigation of men and women. A further improvement is that we had information on socioeconomic indicators for each individual, which was not available previously. ${ }^{78}$ This allowed the identification of a subpopulation that can be expected to be unbiased by smoking. As the results for central nervous system tumours in this group were similar to those we found in all men or women (see table 1), this suggests that smoking or other lifestyle factors represented by education and income are not confounders.
A limitation of the study is potential misclassification of exposure. Subscription holders who are not using their phone will erroneously be classified as exposed and people without a subscription but still using a mobile phone will erroneously be classified as unexposed. Because we excluded corporate subscriptions, mobile phone users who do not have a subscription in their own name will have been misclassified as unexposed. Also, as data on mobile phone subscriptions were available only until 1995, individuals with a subscription in 1996 or later were classified as non-users. No increased risks for central nervous system tumours or glioma, however, were found for subscription holders of $\geq 13$ years compared with non-subscribers, where there is the strongest contrast between exposed and unexposed. Moreover, we conducted an additional analysis restricting follow-up until 31 December 1996, which minimised misclassification of exposure. Although this enormously reduced the number of cases, the results were similar. For example, the incidence rate ratio in men for central nervous system tumours was 1.07 (95\% confidence interval 0.86 to $1.34 ; \mathrm{n}=83$ ), and for glioma it was 1.08 ( 0.77 to 1.51 ; $\mathrm{n}=36$ ). In addition, using a one year latency for mobile phone use reduced potential bias from reverse causation.

Another limitation of our study is that the dose- response analyses are based on years since first subscription and we did not have information on the actual amount of mobile phone use. Therefore, we could not examine the risk restricted to the subgroup of heaviest users. One might assume that the high costs related to mobile phone use during the introduction period might have caused subscribers to refrain from extensive use of their mobile phones. Interestingly, we found indications that early subscription holders before 1995 were in fact heavier users (based on outgoing calls) compared with all subscription holders in the years 1996-2002. ${ }^{24}$ The weekly average length of outgoing calls was 23 minutes for subscribers in 1987-95 and 17 minutes in 1996-2002. In addition, early subscription holders were on average more exposed to radio frequency electromagnetic fields from their mobile phones as the early phones had a higher output power than newer generation phones. ${ }^{25}$ As handheld mobile phones were introduced only in 1987 and we focused on central nervous system tumours, assessment of exposure was improved by left censoring exposure data to 1987 , thereby reducing misclassification of exposure from car phones. Car phones were available in Denmark from 1982 but in terms of cranial exposure to radio frequency electromagnetic fields are several orders of magnitude lower than handheld mobile phones. We did not, however, have information on the use of cordless phones, which operate in a similar frequency range to mobile phones, or on the use of hands-free kits, with which exposure to the head and therefore the brain is greatly reduced. ${ }^{26}$ Misclassification of exposure in this study is likely to be non-differential, leading to a dilution of effects, whereas in the existing case-control studies there are biases that inflate or deflate effect estimates, which severely limits the interpretation of the findings. ${ }^{56} \mathrm{In}$ addition, a validation study using self reported mobile phone use from 822 people in the control group in the Danish Interphone study showed that subscription holders were about four times more likely to report regular mobile phone use (defined as making or receiving at least one call a week over a period of six months or more) before 1996 compared with the general Danish population. ${ }^{8}$ Moreover, the results of this validation study confirmed that our approach to classifying exposure is appropriate to show or rule out moderate or large risks related to mobile phone use. ${ }^{11}$ 


\section{What is already known on this topic}

Results from epidemiological studies on the association between mobile phone use and the risk of tumours of the central nervous system are inconclusive, particularly regarding long term use

Previous mainly case-control studies included small numbers of long term users and were prone to error and bias

\section{What this study adds}

This large population based cohort study uses data from existing registers and virtually eliminates participation and recall bias associated with previous studies

There was no association between tumours of the central nervous system or brain and long term ( $\geq 10$ years) use of mobile phones

\section{Conclusions and outlook}

In conclusion, in this update of a nationwide study of mobile phone subscribers in Denmark we found no indication of an increased risk of tumours of the central nervous system. The extended follow-up allowed us to investigate effects in people who had used mobile phones for 10 years or more, and this long term use was not associated with higher risks of cancer.

Furthermore, we found no increased risk in temporal glioma, which would be the most plausible tumour location if mobile phone use was a risk. As a small to moderate increase in risk for subgroups of heavy users or after even longer induction periods than 10-15 years cannot be ruled out, however, further studies with large study populations, where the potential for misclassification of exposure and selection bias is minimised, are warranted.

We thank the steering committee of the Danish cohort study on social inequality and cancer (cancer og social ulighed-CANULI) for providing the cohort data. We thank Lene Mellemkjær and Søren Friis for support with topography and morphology codes, Susanne Oksbjerg Dalton and Kathrine Grell for feedback on the manuscript draft, and Luise Cederkvist Kristiansen for support with drafting figure 2.

Contributors: $\mathrm{JHO}$ and CJ established the nationwide cohort of mobile subscription holders. JS had the idea for this study. PF was responsible for data management and statistical analyses and drafted the article. AHP did data management and statistical analyses. MS-J supported statistical analyses related to the CANULI cohort. All authors commented on and approved the final draft. PF is guarantor.

Funding: This study was funded by the Danish Strategic Research Council (grant No 09-059984, 09-059045) to cover costs for data linkage. PF received a fellowship for prospective researchers by the Swiss National Science Foundation for this project. AHP was supported by a stipend for PhD students from the Danish Graduate School in Public Health Science. All other authors contributed to this work based on their respective core budget positions.

Competing interests: All authors have completed the ICMJE uniform disclosure form at www.icmje.org/coi_disclosure.pdf (available on request from the corresponding author) and declare: no support from any organisation for the submitted work; no financial relationships with any organisations that might have an interest in the submitted work in the previous three years; no other relationships or activities that could appear to have influenced the submitted work.

Ethical approval: The study was approved by the Danish ethical committee system (KF 01-075/96), the Danish Data Protection Board (1996-1200-121), and the Danish Ministry of Justice (Jnr. 1996-760-0219).

Data sharing: No additional data available.

International Telecommunication Union (ITU). Key global telecom indicators for the world telecommunication service sector. 2010. www.itu.int/ITU-D/ict/statistics/at glance/ KeyTelecom.html.
2 Scientific Committee on Emerging and Newly Identified Health Risks. Health effects of exposure to EMF. European Commission, 2009.

3 INTERPHONE Study Group. Brain tumour risk in relation to mobile telephone use: results of the INTERPHONE international case-control study. Int J Epidemiol 2010;39:675-94.

4 Ahlbom A, Feychting M, Green A, Kheifets L, Savitz DA, Swerdlow AJ. Epidemiologic evidence on mobile phones and tumor risk: a review. Epidemiology 2009;20:639-52.

5 Vrijheid M, Deltour I, Krewski D, Sanchez M, Cardis E. The effects of recall errors and of selection bias in epidemiologic studies of mobile phone use and cancer risk. J Expo Sci Environ Epidemiol 2006;16:371-84.

6 Vrijheid M, Armstrong BK, Bedard D, Brown J, Deltour I, lavarone I, et al. Recall bias in the assessment of exposure to mobile phones. J Expo Sci Environ Epidemiol 2009;19:369-81.

7 Johansen C, Boice J Jr, McLaughlin J, Olsen J. Cellular telephones and cancer-a nationwide cohort study in Denmark. J Natl Cancer Inst 2001;93:203-7.

8 Schüz J, Jacobsen R, Olsen JH, Boice JD Jr, McLaughlin JK, Johansen C. Cellula telephone use and cancer risk: update of a nationwide Danish cohort. J Natl Cancer Inst 2006;98:1707-13.

9 Oksbjerg Dalton S, Steding-Jessen M, Gislum M, Frederiksen K, Engholm G, Schüz J. Social inequality and incidence of and survival from cancer in a population-based study in Denmark, 1994-2003: background, aims, materials and methods. Eur J Cancer 2010;44:1938-49.

10 Schüz J, Waldemar G, Olsen JH, Johansen C. Risks for central nervous system diseases among mobile phone subscribers: a Danish retrospective cohort study. PLoS One 2009;4:e4389.

11 Schüz J, Johansen C. A comparison of self-reported cellular telephone use with subscriber data: agreement between the two methods and implications for risk estimation. Bioelectromagnetics 2007;28:130-6.

12 Schüz J, Steding-Jessen M, Hansen S, Stangerup SE, Caye-Thomasen P, Poulsen AH, et al. Long-term mobile phone use and the risk of vestibular schwannoma: a Danish nationwide cohort study. Am J Epidemiol 2011;174:416-22.

13 Storm HH, Michelsen EV, Clemmensen IH, Pihl J. The Danish Cancer Registry-history, content, quality and use. Dan Med Bull 1997;44:535-9.

14 National Board of Health. Cancer incidence in Denmark 2001; health statistics 2006. National Board of Health (Denmark), 2006.

15 World Health Organization. International classification of diseases for oncology (ICD-O) WHO, 1976.

16 Cardis E, Deltour I, Mann S, Moissonnier M, Taki M, Varsier N, et al. Distribution of RF energy emitted by mobile phones in anatomical structures of the brain. Phys Med Biol 2008;53:2771-83

17 Olsen JH, Friis S, Frederiksen K, McLaughlin JK, Mellemkjær L, Moller H. A typical cancer pattern in patients with Parkinson's disease. Br J Cancer 2005;92:201-5.

18 Hardell L, Carlberg M, Hansson MK. Mobile phone use and the risk for malignant brain tumors: a case-control study on deceased cases and controls. Neuroepidemiology 2010:35:109-14.

19 Inskip PD, Tarone RE, Hatch EE, Wilcosky TC, Shapiro WR, Selker RG, et al. Cellular-telephone use and brain tumors. N Engl J Med 2001;344:79-86.

20 Deltour I, Johansen C, Auvinen A, Feychting M, Klaeboe L, Schuz J. Time trends in brain tumor incidence rates in Denmark, Finland, Norway, and Sweden, 1974-2003. J Natl Cancer Inst 2009;101:1721-4

21 Inskip PD, Hoover RN, Devesa SS. Brain cancer incidence trends in relation to cellular telephone use in the United States. Neuro Oncol 2010;12:1147-51

22 Lönn S, Klaeboe L, Hall P, Mathiesen T, Auvinen A, Christensen HC, et al. Incidence trends of adult primary intracerebral tumors in four Nordic countries. Int $\mathrm{J}$ Cancer 2004;108:450-5.

23 Röösli M, Michel G, Kuehni CE, Spoerri A. Cellular telephone use and time trends in brain tumour mortality in Switzerland from 1969 to 2002. Eur J Cancer Prev 2007:16:77-82.

24 National IT and Telecom Agency. Tele yearbook, Denmark. National IT and Telecom Agency, 2001

25 Neubauer G, Cecil S, Giczi W, Petric B, Preiner P, Frohlich J, et al. The association between exposure determined by radiofrequency personal exposimeters and human exposure: a simulation study. Bioelectromagnetics 2010;31:535-45

26 Kühn S, Cabot E, Christ A, Capstick M, Kuster N. Assessment of the radio-frequency electromagnetic fields induced in the human body from mobile phones used with hands-free kits. Phys Med Biol 2009;54:5493-508.

Accepted: 12 September 2011

\section{Cite this as: BMJ 2011;343:d6387}

This is an open-access article distributed under the terms of the Creative Commons Attribution Non-commercial License, which permits use, distribution, and reproduction in any medium, provided the original work is properly cited, the use is non commercial and is otherwise in compliance with the license. See: http://creativecommons.org/licenses/bync/2.0/ and http://creativecommons.org/licenses/by-nc/2.0/legalcode. 


\section{Tables}

Table 1 | Overall incidence rate ratios ( $95 \%$ confidence intervals) for all cancers, smoking related cancers, and tumours of central nervous system among mobile phone subscribers in Denmark, 1987-95, followed up to 31 December 2007, for men, women, and men with more than 12 years of education

\begin{tabular}{|c|c|c|c|c|c|c|}
\hline \multirow[b]{2}{*}{ Site of cancer } & \multicolumn{2}{|r|}{$\operatorname{Men}^{\star}$} & \multicolumn{2}{|c|}{ Woment } & \multicolumn{2}{|c|}{ Men with $>12$ years of education $¥$} \\
\hline & Cases & Incidence rate ratio§ & Cases & Incidence rate ratio§ & Cases & Incidence rate ratio§ \\
\hline \multicolumn{7}{|l|}{ All cancersף } \\
\hline Non-subscribers & 107840 & 1 & 130918 & 1 & 17063 & 1 \\
\hline Subscribers & 14462 & 0.96 (0.95 to 0.98$)$ & 2795 & 1.02 (0.98 to 1.06$)$ & 2402 & $1.02(0.97$ to 1.06$)$ \\
\hline \multicolumn{7}{|c|}{ Years of subscription: } \\
\hline $1-4$ & 2855 & $0.96(0.92$ to 1.00$)$ & 717 & $1.02(0.95$ to 1.10$)$ & 482 & $1.06(0.97$ to 1.16$)$ \\
\hline $5-9$ & 5291 & $0.93(0.91$ to 0.96$)$ & 1203 & $1.03(0.97$ to 1.09$)$ & 890 & $1.00(0.94$ to 1.07$)$ \\
\hline$\geq 10$ & 6316 & 0.99 (0.97 to 1.02$)$ & 875 & $1.00(0.93$ to 1.06$)$ & 1030 & $1.01(0.95$ to 1.08$)$ \\
\hline $10-12$ & 4033 & 0.99 (0.96 to 1.02$)$ & 721 & 0.99 (0.92 to 1.07$)$ & 647 & $0.99(0.91$ to 1.07$)$ \\
\hline$\geq 13$ & 2283 & $1.00(0.96$ to 1.04$)$ & 154 & $1.00(0.85$ to 1.17$)$ & 383 & $1.04(0.94$ to 1.16$)$ \\
\hline \multicolumn{7}{|c|}{ All smoking related sites ${ }^{* *}$} \\
\hline Non-subscribers & 44247 & 1 & 33175 & 1 & 5449 & 1 \\
\hline Subscribers & 5422 & $0.93(0.90$ to 0.96$)$ & 685 & $1.06(0.98$ to 1.14$)$ & 731 & $1.01(0.93$ to 1.09$)$ \\
\hline \multicolumn{7}{|c|}{ Years of subscription: } \\
\hline $1-4$ & 1118 & 0.93 (0.87 to 0.99$)$ & 185 & $1.17(1.02$ to 1.36$)$ & 152 & 1.04 (0.88 to 1.23$)$ \\
\hline $5-9$ & 2041 & 0.93 (0.89 to 0.97$)$ & 292 & $1.06(0.95$ to 1.19$)$ & 285 & 1.05 (0.93 to 1.18$)$ \\
\hline$\geq 10$ & 2263 & $0.93(0.89$ to 0.97$)$ & 208 & 0.97 (0.85 to 1.12$)$ & 294 & $0.95(0.85$ to 1.08$)$ \\
\hline $10-12$ & 1495 & 0.97 (0.92 to 1.02$)$ & 165 & 0.94 (0.80 to 1.09$)$ & 199 & $1.02(0.88$ to 1.17$)$ \\
\hline$\geq 13$ & 768 & 0.87 (0.81 to 0.93$)$ & 43 & $1.15(0.85$ to 1.55$)$ & 95 & $0.85(0.69$ to 1.04$)$ \\
\hline \multicolumn{7}{|c|}{ Central nervous system $+\dagger$} \\
\hline Non-subscribers & 4397 & 1 & 5486 & 1 & 850 & 1 \\
\hline Subscribers & 714 & $1.02(0.94$ to 1.10$)$ & 132 & 1.02 (0.86 to 1.22$)$ & 120 & $1.00(0.83$ to 1.22$)$ \\
\hline \multicolumn{7}{|c|}{ Years of subscription: } \\
\hline $1-4$ & 180 & 1.07 (0.92 to 1.24$)$ & 34 & 0.97 (0.69 to 1.36$)$ & 38 & $1.29(0.92$ to 1.79$)$ \\
\hline $5-9$ & 258 & 0.95 (0.83 to 1.08$)$ & 58 & 1.05 (0.81 to 1.37$)$ & 44 & $0.95(0.70$ to 1.29$)$ \\
\hline$\geq 10$ & 276 & $1.06(0.94$ to 1.20$)$ & 40 & $1.03(0.75$ to 1.40$)$ & 38 & $0.86(0.62$ to 1.20$)$ \\
\hline $10-12$ & 187 & $1.08(0.93$ to 1.25$)$ & 34 & $1.05(0.75$ to 1.47$)$ & 24 & $0.82(0.55$ to 1.24$)$ \\
\hline$\geq 13$ & 89 & $1.03(0.83$ to 1.27$)$ & 6 & 0.91 (0.41 to 2.04 ) & 14 & $0.94(0.55$ to 1.60$)$ \\
\hline
\end{tabular}

*Men: 18829804 person years for non-subscribers, 3229589 person years for subscribers (person years by years of subscription: 1-4=893 248, 5-9=1 284 238, $\geq 10=1052$ 103, 10-12: 747 444, $\geq 13=304$ 659).

†Women: 21304186 person years for non-subscribers, 533733 person years for subscribers (person years by years of subscription: 1-4=164 507, 5-9=225 864, $\geq 10=143361,10-12=121529, \geq 13=21832$ ).

‡Subgroup: 3645725 person years for non-subscribers, 503162 person years for subscribers (person years by years of subscription: 1-4=145 818, 5-9=197 710, $\geq 10=159634,10-12=111053, \geq 13=48582$ ).

§Adjusted for age, calendar period, level of education, and disposable income.

IICD-10 codes C00-D48.

${ }^{*}$ ICD-10 codes C09-16, C22, C25, C32-34, C39, C53, C64, C67, D09.0, D30.3, D41.4

††ICD-10 codes C70-72, C75, D32-33, D35, D42, D44. 
Table 2| Incidence rate ratios (95\% confidence intervals) for intracranial tumours of central nervous system categorised according to ICD-O morphology and topography codes among men and women with mobile phone subscriptions in Denmark, 1987-95, followed up to 31 December 2007

\begin{tabular}{|c|c|c|c|c|}
\hline \multirow[b]{2}{*}{ Tumour category } & \multicolumn{2}{|r|}{ Men* } & \multicolumn{2}{|r|}{ Women* } \\
\hline & Cases & Incidence rate ratio† & Cases & Incidence rate ratio† \\
\hline \multicolumn{5}{|l|}{ Glioma‡ } \\
\hline Non-subscribers & 1853 & 1 & 1455 & 1 \\
\hline Subscribers & 324 & 1.08 (0.96 to 1.22$)$ & 32 & $0.98(0.69$ to 1.40$)$ \\
\hline \multicolumn{5}{|l|}{ Years of subscription: } \\
\hline $1-4$ & 85 & $1.20(0.96$ to 1.50$)$ & 8 & $0.87(0.43$ to 1.75$)$ \\
\hline $5-9$ & 122 & 1.05 (0.87 to 1.26$)$ & 14 & $1.02(0.60$ to 1.72$)$ \\
\hline$\geq 10$ & 117 & $1.04(0.85$ to 1.26$)$ & 10 & 1.04 (0.56 to 1.95$)$ \\
\hline $10-12$ & 80 & $1.06(0.85$ to 1.34$)$ & NA & - \\
\hline$\geq 13$ & 37 & $0.98(0.70$ to 1.36$)$ & NA & 一 \\
\hline \multicolumn{5}{|l|}{ Meningioma§ } \\
\hline Non-subscribers & 429 & 1 & 1248 & 1 \\
\hline Subscribers & 50 & 0.78 (0.58 to 1.05$)$ & 30 & $1.02(0.71$ to 1.47$)$ \\
\hline \multicolumn{5}{|c|}{ Years of subscription: } \\
\hline $1-4$ & 15 & $0.92(0.55$ to 1.56$)$ & 9 & 1.08 (0.56 to 2.09$)$ \\
\hline $5-9$ & 14 & $0.56(0.33$ to 0.96$)$ & 13 & $1.04(0.60$ to 1.79$)$ \\
\hline$\geq 10$ & 21 & $0.90(0.57$ to 1.42$)$ & 8 & $0.93(0.46$ to 1.87$)$ \\
\hline \multicolumn{5}{|c|}{ Other and unspecified $\mathbb{T}$} \\
\hline Non-subscribers & 968 & 1 & 1297 & 1 \\
\hline Subscribers & 162 & $1.12(0.95$ to 1.33$)$ & 35 & $1.19(0.85$ to 1.67$)$ \\
\hline \multicolumn{5}{|l|}{ Years of subscription: } \\
\hline $1-4$ & 37 & 1.09 (0.78 to 1.53$)$ & 7 & 0.95 (0.45 to 2.00$)$ \\
\hline $5-9$ & 60 & $1.08(0.83$ to 1.40$)$ & 16 & $1.28(0.78$ to 2.09$)$ \\
\hline$\geq 10$ & 65 & $1.19(0.92$ to 1.55$)$ & 12 & 1.27 (0.72 to 2.25$)$ \\
\hline
\end{tabular}

$\mathrm{NA}=$ not applicable (numbers too small for analyses).

*See table 1 for person years for men and women.

†Adjusted for age, calendar period, level of education, and disposable income.

ҒICD-O topography codes C71.0-71.9 and morphology codes 93803-94813.

§ICD-O topography codes C70 and morphology codes 93803-94813.

TPineal gland (C75.3) and other morphologies for $\mathrm{C} 70$ and $\mathrm{C} 71.0-9$. 
Table 3 | Incidence rate ratios ( $95 \%$ confidence intervals) for gliomas by anatomical site among male mobile phone subscribers ${ }^{\star}$ in Denmark, 1987-95, followed up to 31 December 2007

\begin{tabular}{|c|c|c|}
\hline Site (code) & Cases & Incidence rate ratio† \\
\hline \multicolumn{3}{|l|}{ Cerebrum (C71.0) } \\
\hline Non-subscribers & 375 & 1 \\
\hline Subscribers & 52 & 0.90 (0.67 to 1.22$)$ \\
\hline \multicolumn{3}{|c|}{ Frontal lobe (C71.1) } \\
\hline Non-subscribers & 431 & 1 \\
\hline Subscribers & 79 & $1.13(0.89$ to 1.45$)$ \\
\hline \multicolumn{3}{|c|}{ Temporal lobe (C71.2) } \\
\hline Non-subscribers & 363 & 1 \\
\hline Subscribers & 65 & $1.13(0.86$ to 1.48$)$ \\
\hline \multicolumn{3}{|c|}{ Parietal lobe (C71.3) } \\
\hline Non-subscribers & 293 & 1 \\
\hline Subscribers & 33 & 0.73 (0.50 to 1.05$)$ \\
\hline \multicolumn{3}{|c|}{ Occipital lobe (C71.4) } \\
\hline Non-subscribers & 81 & 1 \\
\hline Subscribers & 18 & 1.47 (0.87 to 2.48$)$ \\
\hline \multicolumn{3}{|c|}{ Others and unspecified (C71.5-C71.9) } \\
\hline Non-subscribers & 310 & 1 \\
\hline Subscribers & 77 & 1.35 (1.05 to 1.75$)$ \\
\hline \multicolumn{3}{|c|}{$\begin{array}{l}\text { *See table } 1 \text { for person years. } \\
\text { †Adjusted for age, calendar period, level of education, and disposable income. }\end{array}$} \\
\hline
\end{tabular}




\section{Figures}

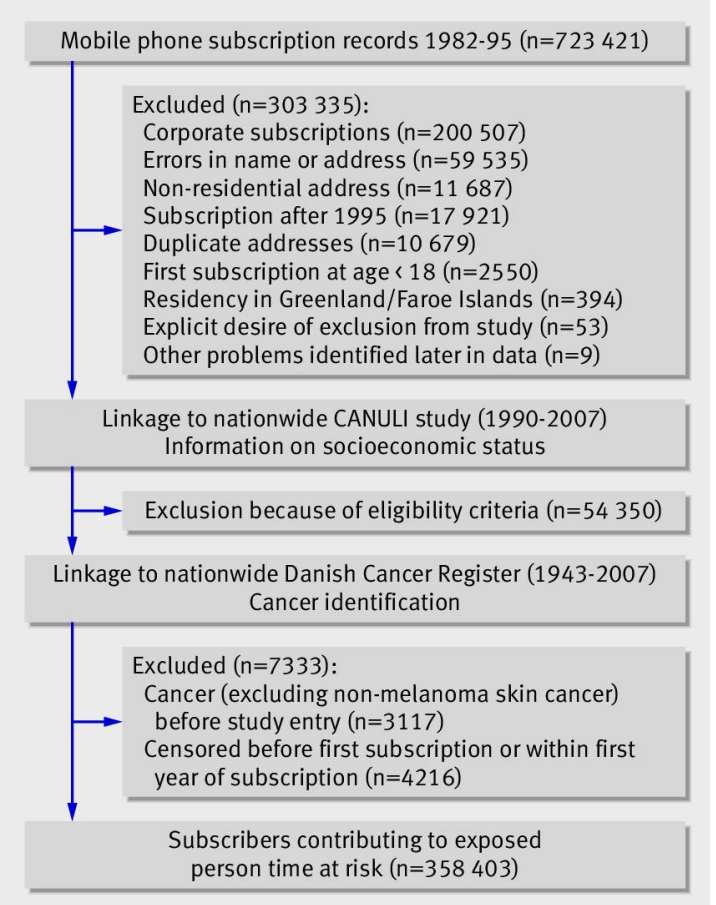

Fig 1 Details of determination of final sample contributing to exposed person time

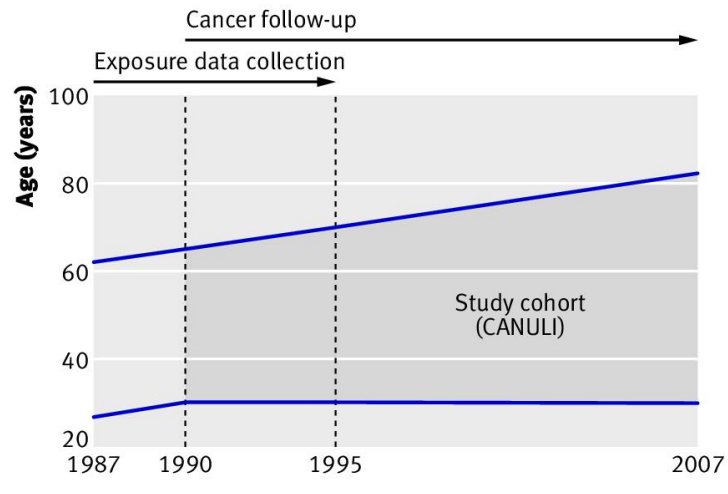

Calendar year

Fig 2 Definition of study cohort and periods of collection of exposure data and follow-up for cancer outcome by age and time. Shaded area represents time span for which data on socioeconomic indicators were available for members of CANULI cohort 